\title{
PROCESSO DE TRABALHO DO ENFERMEIRO FRENTE AO NOVO PROTOCOLO DE MORTE ENCEFÁLICA E DOAÇÃO DE ÓRGÃOS
}

\author{
Priscila Mara Scagliusi ${ }^{1}$ \\ Nicássia Senhorini Magalhães ${ }^{1}$ \\ Luiza Venturini Helaehil \\ Clarice Santana Milagres ${ }^{1}$ \\ ${ }^{1}$ Enfermagem - Centro Universitário Fundação Hermínio Ometto- Uniararas
}

INTRODUÇÃO: A morte é compreendida como a ausência de batimentos cardíacos e movimentos respiratórios, pode-se com os avanços científicos, estudar e compreender que a morte também pode ocorrer por meio da cessação do funcionamento do encéfalo. A morte encefálica representa a ausência de funcionamento cerebral, há a inexistência de atividade elétrica na região do encéfalo e o paciente somente consegue sobreviver devido a meios artificiais. Os pacientes com morte encefálica podem permanecer com a função cardiorrespiratória intacta temporariamente. A morte consiste em um processo difícil e, em muitas situações, a não aceitação da fase de finitude e as esperanças de cura são muito notórias, por este motivo, muitas famílias e profissionais da saúde sentem dificuldade em aceitar o diagnóstico de morte encefálica e posterior doação de órgãos, surgem questionamentos quanto à possibilidade do paciente sobreviver. OBJETIVO: O estudo teve como objetivo verificar na literatura o embasamento teórico, atual e consolidado acerca protocolo de morte encefálica, bem como as leis que regem esta temática, inserindo o enfermeiro neste contexto complexo. MÉTODOS: revisão de literatura com artigos publicados entre 2007 e 2017, nas bases de dados eletrônicos PubMed Medline, Scielo Science Direct. Também será utilizado descritores prédeterminados em inglês e em português, abrangendo artigos que utilizassem: "encephalic death", "intensive care", nursing e seus respectivos descritores em português, usados em combinação. As referências bibliográficas dos trabalhos identificados pela pesquisa eletrônica serão revisadas para identificação de estudos adicionais. O presente trabalho foi aprovado pelo Comitê de Ética da Fundação Hermínio Ometto, com o protocolo 861/2017. RESULTADOS: com o novo protocolo de morte encefálica e a resolução do Conselho Regional de Enfermagem, o enfermeiro possui maior empoderamento, autonomia e segurança para atuar juntamente com a sua equipe num processo de doação e captação de órgãos. $O$ 
novo protocolo de morte encefálica passou a ser mais rígido e seguro transmitindo mais segurança para os familiares no momento da decisão; não somente isso, às medidas de educação em saúde, o melhor acolhimento da família doadora e conscientização da equipe, essas medidas podem contribuir para o aumento nos índices de doadores potenciais e efetivos, refletindo positivamente no número de transplantes de órgãos o que, consequentemente, representa a sobrevida de milhares de pessoas. CONCLUSÃO: o enfermeiro com o novo protocolo de morte encefálica e com a Resolução do Cofen tem a oportunidade de possuir maior embasamento teórico e autonomia já que este profissional é um membro fundamental da equipe multiprofissional, devendo atuar em todas as fases do protocolo; A educação em saúde é um grande aliado do enfermeiro e deve ser usada em vários ambientes, desmistificando a crença errônea da população.

Descritores: Morte encefálica. Cuidado intensivo. Enfermagem. 